\title{
Resenha/Review
}

\section{BORBA, Rodrigo (2016) O (Des)Aprendizado de Si: transexualidades, interação e cuidado em saúde. Rio de Janeiro: Editora Fiocruz.}

\author{
Por/By: Daniel do Nascimento e Silva ${ }^{1,2}$
}

Como nos tornamos sujeitos viáveis? Com nuances variadas, essa pergunta - que desloca a questão da subjetividade do 'ser' para o 'tornar-se' ou o 'aprender' - tem orientado posições marcantes em filosofias socioconstrucionistas da vida social, dentre elas a crítica filosófica de Friedrich Nietzsche, a arqueologia do sujeito de Michel Foucault, a desconstrução do gênero de Judith Butler e a indisciplina linguístico-aplicada de Luiz Paulo da Moita Lopes. Ser viável, diz o dicionário Michaelis, é biologicamente aquilo "que pode germinar, crescer e se desenvolver"; é, em sentido figurado, algo "que se pode realizar" e algo "duradouro". Pelo menos semanticamente, ser um sujeito viável aponta para se desenvolver de uma dada maneira, figurativamente de forma prática e duradoura.

Mas o que dizer da viabilidade do sujeito - isto é, do seu florescimento prático e temporal - para além do conforto das entradas do

1. Universidade Federal de Santa Catarina, Programa de Pós-Graduação em Linguística, Departamento de Língua e Literatura Vernáculas, Florianópolis - SC - Brasil. https://orcid.org/0000-0002-6098-5185. E-mail: dnsfortal@gmail.com.

2. Universidade Federal do Rio de Janeiro, Programa Interdisciplinar de Pós-Graduação em Linguística Aplicada, Rio de Janeiro, RJ - Brasil. 
dicionário? O que dizer das tramas, dos ruídos e das fricções (Fabrício, 2014) da viabilidade em seu uso ordinário e por vezes violento? Como pensar a sobrevivência - esta também uma forma de viabilidade? - de sujeitos ou pessoas transexuais no país que mais mata essa população no mundo? Como entender o processo pelo qual pessoas se tornam transexuais verdadeiros, ou seja, sujeitos que se conformam a normas, dispositivos e metadiscursos que regimentam sua viabilidade para, assim e somente assim, receberem cuidado em saúde pública, em especial o acesso a cirurgias de transgenitalização? O que dizer da aparência de substância, efeito de uma trajetória em que se (des)aprende a ser quem se é, toda ela feita de repetições?

Extraio essas perguntas do livro de Rodrigo Borba, $O$ (Des) Aprendizado de Si: transexualidades, interação e cuidado em saúde, um trabalho contemporâneo produzido no campo transdisciplinar (e indisciplinar, diria o orientador da tese que deu origem ao livro, Luiz Paulo da Moita Lopes) da linguística aplicada, em seu estreito diálogo com os projetos epistêmicos da antropologia linguística, da análise da conversa etnometodológica, da filosofia e da saúde pública. Resultado de uma pesquisa etnográfica realizada entre setembro de 2009 e outubro de 2010 no Programa de Atenção Integral à Saúde Transexual (PAIST) ${ }^{3}$, um centro de referência de cuidado à saúde de pessoas transexuais numa grande cidade no Brasil, o livro é uma investigação densa do Processo Transexualizador, i.e., o rígido processo (constituído por dois anos de atendimento mensal com equipe multiprofissional) a que pessoas transexuais se submetem visando às cirurgias de transgenitalização e à hormonoterapia. Centrado em protocolos científicos, médicos e jurídicos que viajam de instituições como a Associação Americana de Psiquiatria (APA), a Organização Mundial de Saúde (OMS), a World Professional Association for Transgender Health (WPATH) e os Departamentos de Sociologia e Psiquiatria da Universidade da Califórnia em Los Angeles (UCLA) até o Conselho Federal de Medicina do Brasil (CFM) e o Sistema Único de Saúde (SUS), o Processo Transexualizador é também um dispositivo - i.e., "um conjunto heterogêneo de práticas discursivas e não discursivas que possuem uma função estratégica de

3. Por necessidade de brevidade, instituições, processos e documentos também conhecidos por acrônimos e siglas serão designados, após sua primeira designação completa, por sua forma mais curta. 
dominação" (Foucault 2013, apud Borba, p.32 $2^{4}$ - que transforma uma imensa gama de desejos, práticas, vivências, ambivalências, prazeres e dores em uma "narrativa de transexual verdadeiro" (p. 32). A partir de ampla evidência empírica, Rodrigo Borba investiga o palco do Processo Transexualizador (sobretudo a partir da análise conversacional de consultas no PAIST de pessoas transexuais com profissionais da área de psiquiatria, endocrinologia e psicologia e da análise textual de documentos que regimentam o programa) bem como seus bastidores (a partir de entrevistas com médicos e psicóloga do PAIST e com transexuais participantes do Processo, além de observação participante de rotinas do hospital, da interação de transexuais e da investigação da história do dispositivo biomédico da transexualidade) e mostra que se tornar um transexual verdadeiro, apto à redesignação sexual, é um processo iterável, calcado num modelo metapragmático biomédico que não necessariamente se conforma às "ambiguidades da vida social generificada" (p.195), nem a "formas locais e contingentes de vivenciar as transexualidades" (p.169).

O estudo traz para o foco o problema da socialização na linguagem. Existe já uma tradição de estudos nessa área, iniciada por uma equipe transdisciplinar que tem estendido o foco dos estudos de aquisição de linguagem para além do aparato formal da/s língua/s a que a criança é exposta no nascimento. Como comentam Elinor Ochs \& Bambi Schieffelin (2008:3), os/as pesquisadores/as do campo da socialização da linguagem - informados/as não apenas por hipóteses sobre a aquisição da língua, mas também pela teorização sobre as condições sociais, culturais e ideológicas em que esse conhecimento é adquirido - passaram a levantar questões que tinham a ver "com a necessidade de as crianças adquirirem as habilidades culturalmente requeridas para participar em sociedade, incluindo formas apropriadas de agir, sentir e pensar." O problema de socialização que Borba levanta, no entanto, vai além do escopo dos estudos habituais desse paradigma, uma vez que ele observa empiricamente "as habilidades culturalmente requeridas" não às crianças, mas a pessoas adultas - para participar de um grupo governado por um dispositivo. Essa extensão etária, por assim dizer, do conceito de socialização já está presente nos estudos de Stanton Wor-

4. Para manter-me breve, as citações à obra resenhada dar-se-ão no formato "Borba, $p$. X" ou apenas "p. X", quando for evidente que o referente é a obra em questão. 
tham (e.g., 2005), com quem Borba dialoga em sua obra; nos termos de Wortham, tornar-se um membro competente de uma comunidade de fala envolve não apenas a socialização cultural observada por Ochs \& Schieffelin, mas também cadeias intertextuais. No Brasil, Claudia Lemos tem problematizado a noção de aquisição como aprendizagem compartimentada e gradual do conhecimento da língua, bem como questiona a diferença entre os processos de subjetivação da criança e do adulto vis-à-vis sua condição como sujeito falante, a fala do Outro e a estrutura da língua: "nenhuma [dessas] relações estruturais [...] deixa de comparecer na fala adulta, que está longe de se manter homogênea através de diferentes tipos de discursos e situações" (Lemos 2006:31). Embora Borba não siga o paradigma estrutural-psicanalítico inaugurado por Lemos, sua proposta parte de uma visão - comungada por Wortham e outros/as pesquisadores/as - de que compreender processos de subjetivação implica entender que a linguagem é, como propôs Sapir, "uma grande força de socialização, talvez a mais forte que exista" (Sapir 1933:15).

Nesta resenha, minha posição é a de que os principais achados desta obra - primeira no Brasil a investigar o Processo Transexualizador a partir de microetnografia de interações-chave, nas quais o (des) aprendizado se realiza - derivam de uma posição inovadora adotada pelo autor nos estudos em linguística aplicada brasileiros. Tal posição implicou determinados modos de lidar com escolhas teóricas, desenhos metodológicos e disposições políticas que, creio eu, são exemplares para os estudos da linguagem contemporâneos. Reconhecida pelo Prêmio Capes de Teses, que laureou a tese na área de Letras e Linguística em 2015, esta obra, mais especificamente, articula de forma exemplar temas como socialização em linguagem, semiose entre encontros e escala. A obra apresenta ainda uma interessante análise situada de recursos sociolinguísticos da vida cotidiana, como a "mentira" e a leitura e entextualização de textos de autoridade de uma cultura. Em vista da relevância desses temas para pesquisas em linguagem que se interessem pelo aprendizado de (e socialização em) determinados signos de identidade - e.g., como ser branco, homem e heterossexual numa escola brasileira (Moita Lopes 2006a), como fazer parte de uma hierarquia de gênero em Samoa e nos Estados Unidos (Ochs 1992), como ser uma adolescente latina envolvida em uma gangue nos Estados Unidos (Mendoza-Denton 2008) - o restante desta resenha será dedica- 
do ao escrutínio de seus potenciais na obra, dado o modo inovador que Borba os articula a partir de denso trabalho empírico. Antes, porém, oferecerei uma breve visão geral do livro.

\section{Visão Geral}

O (Des)Aprendizado de Si: transexualidades, interação e cuidado em saúde está dividido em seis capítulos. Contém ainda um Prefácio de Luiz Paulo da Moita Lopes, um posfácio de Flávia Teixeira e um texto de "orelha" de Ana Cristina Ostermann. O primeiro capítulo discute a emergência do dispositivo da transexualidade, um conjunto de sistemas de conhecimento, configurações de poder e formas de governo que tornaram a transexualidade um fenômeno visível a partir de sua patologização. O segundo capítulo narra a especificidade do Processo Transexualizador brasileiro e a intricada construção da pesquisa de campo. O terceiro capítulo apresenta evidência empírica sobre trajetórias de socialização, nas quais as/os usuárias/os do PAIST se tornam transexuais verdadeiros, a partir de uma vinheta etnográfica fundamental para a argumentação subsequente do livro. Nessa vinheta, Vitória, uma usuária neófita do Processo Transexualizador, aprende com usuárias mais antigas como passar por um transexual verdadeiro; a partir de barreiras erigidas pela burocracia do sistema, a usuária precisará vencer uma longa cadeia de fricções e poderes conectados intertextualmente.

O capítulo quatro avança o argumento de que a produção da linearidade entre a interação produzida com os profissionais do PAIST e o modelo biomédico que regimenta a narrativa de transexual verdadeiro "é um trabalho árduo e contínuo que se espalha por todo o Processo, constituindo, assim, uma trajetória de socialização." (p. 113). Neste capítulo, Borba centra-se nas consultas com a equipe de saúde mental de forma a demonstrar sua função de gatekeepers desses profissionais. É essa equipe que, afinal, irá aferir e legitimar se as performances semióticas locais das/dos participantes do programa se adequam ao modelo legítimo de identidade de gênero previsto nos protocolos da APA e do CFM. O quinto capítulo discute a função interacional da "mentira" no Processo Transexualizador. Nesse capítulo, Borba retorna a um clássico da literatura etnometodológica, Studies in Ethnometodology, de 
Gafinkel (1967). Borba retoma aqui a centralidade da interação entre Garfinkel e Agnes, uma participante da Clínica de Gênero da UCLA, para a solidificação da verdade sobre a transexualidade. Os efeitos das mentiras de Agnes na narrativa do sociólogo são comparados à função pragmática das mentiras de Marcia Rejane, uma usuária do PAIST que Borba acompanha no palco e nos bastidores do Processo Transexualizador. Tanto este capítulo quanto a conclusão se dedicam a demonstrar que a complexidade dialógica e pragmática das vivências trans requerem um tratamento humanizado, tanto do SUS quanto da pesquisa que contribui para a produção de seus efeitos de verdade.

\section{Discussão}

Como comentei, o desenho metodológico desta obra foi fundamental para que temas fundamentais da pesquisa contemporânea em linguagem - como socialização em linguagem, semiose entre encontros e escala - fossem mostrados nas dinâmicas de poder e resistência da interação (e nos bastidores dela) em vez de idealizados. Pesquisas em linguagem correm o risco de caírem em uma armadilha que o filósofo John L. Austin (1962) chamou de "ilusão referencial": se entendermos que a linguagem espelha o mundo lá fora, ou o descreve de modo verdadeiro ou falso, então bastaria que analisássemos a forma da linguagem (e talvez, munidos de um espírito de jornalista investigativo/a, fôssemos depois conferir se essa forma corresponde com o mundo). No entanto, como Austin demonstrou, muitos dos enunciados que aparentemente descrevem o mundo estão na verdade o produzindo (ou criando as condições para que esse mundo seja inteligível). Fugir da ilusão referencial, para Austin, significaria abraçar o estudo do ato de fala total: "Devemos considerar a situação total em que o enunciado é proferido - o ato de fala total - se quisermos ver os paralelos entre sentenças e enunciados performativos, e como cada um deles pode dar errado." Para o filósofo, é a atenção ao ato de fala total que, em última instância, permitirá a conclusão gradual de que, em termos lógicos, o constativo pode ser assimilado ao performativo: "Então o ato de fala total na situação de fala total está emergindo gradualmente de passos lógicos como algo importante em casos especiais: e portanto estamos assimilando o suposto enunciado constativo ao performativo." 
Contemporaneamente, e a obra de Borba é um importante passo lógico neste caminho, considerar o ato de fala total significa assumir que tanto os enunciados que analisamos em nossas pesquisas quanto os contextos que eles indiciam (ou "o mundo lá fora") são textualmente mediados - o constativo é aquele enunciado que textualmente lemos como "dando uma informação sobre o mundo", o que é um si um processo laminado em camadas e não isento de conflitos e disputas. Nos termos de Borba, a investigação do ato de fala total do Processo Transexualizador significou entender diferentes dimensões e camadas dessa tessitura; significou ainda movimentar-se por diferentes escalas da vida social. As mais importantes delas, a meu ver, são:

- Borba faz uma análise textual dos documentos internacionais nos quais o Processo Transexualizador se baseia. Definindo a transexualidade como uma forma de transtorno psíquico e de gênero, as racionalidades produtoras do modelo de transexual verdadeiro viajam até o CFM e o Ministério da Saúde, cujas portarias regimentam o Processo Transexualizador no Brasil. Indiciando epistemes e dispositivos translocais, os documentos brasileiros regulam - e pela patologização, tornam legível - a transexualidade nas esferas médica e legal no país. A análise textual, no entanto, mostra também o conflito e as camadas desse trânsito de formas de saber/poder: diversas "lutas pela entextualização" (Fabrício 2014) - por exemplo, de movimentos ativistas trans - terminam por produzir nesses documentos ecos de reivindicações despatologizantes.

- Borba realiza uma etnografia linguística que lhe permite ir até os contextos de seu ato de fala total. Dito de outro modo, as racionalidades biomédicas, as ações de profissionais da saúde e as táticas e signos de (des)aprendizagem de pessoas transexuais não são meramente lidos de documentos que ilustram a autoridade biomédica. O que os padrões de textualidade projetam - por exemplo, a escuta de sintomas patológicos - é vivenciado na prática por Borba ao longo de 13 meses de trabalho etnográfico no hospital, em seus corredores, em suas salas de espera, nos quiosques de comida em sua rua principal, bem como na casa de Borba e em outros locais de interação e entrevista. Veja que "vivenciado na prática" não é o mesmo 
"confirmado referencialmente no mundo"; a vivência etnográfica é ela própria textualmente mediada.

- No contexto da etnografia linguística, Borba realiza uma análise da fala em interação, sobretudo de consultas do Processo Transexualizador, e de forma indisciplinar (Moita Lopes 2006b; Fabrício 2017) conecta eventos discretos a outros eventos, demonstrando assim a existência de uma semiose entre encontros, nos quais um signo se movimenta de um lugar a outro e produz uma forma de (des)aprendizado, numa trajetória de socialização.

- Borba faz análise pragmática de recursos sociolinguísticos do dia-a-dia de usuárias/os do PAIST, por exemplo a leitura e entextualização das normas e portarias do Processo Transexualizador e as "mentiras" que as/os usuárias/os contam às/aos profissionais de saúde.

Essas dimensões metodológicas - que são também dimensões teóricas - então levam Borba a inovar, apresentando ao público brasileiro uma etnografia densa que problematiza construtos teóricos contemporâneos, os quais detalho a seguir.

\section{Semiose entre encontros}

A conectividade entre os eventos discretos de que participamos tem sido explorada por estudos que se interessam pelo caráter citacional de nossas práticas situadas. Asif Agha resumiu bem a lógica dessa questão em editorial para um número especial do Journal of Linguistic Anthropology, dedicado ao tema da "semiose entre encontros." Diz o autor:

Todos sabemos que qualquer pessoa que efetivamente se engaja em um dado encontro discursivo já participou de outros antes e portanto traz para o encontro corrente uma história discursiva biograficamente específica que, em vários aspectos, modela a habilidade socializada do indivíduo de usar e produzir enunciados (assim como alinhamentos, avaliações, identidades e relacionamentos mediados por enunciados) dentro do encontro corrente; e se o encontro corrente oferece quaisquer consequências ulteriores para 
o indivíduo, estas são manifestas em (e portanto identificáveis apenas ao considerar) futuros encontros em que aquele indivíduo desempenha um papel (Agha 2005:1).

Retomarei a vinheta etnográfica do capítulo 3 para explicar as consequências analíticas e epistêmicas de considerar a "história discursiva biograficamente específica" de um indivíduo para analisar o evento discursivo. Nessa vinheta, composta de duas cenas, Borba demonstra aspectos do desaprendizado de signos de identidade - isto é, a substituição de signos pouco autênticos da transexualidade, em termos biomédicos, por aqueles prototípicos do modelo de transexual verdadeiro - na história interacional de Vitória, uma participante neófita no Processo Transexualizador. Na primeira cena, extraída de seus cadernos de campo, Borba está tomando café da manhã com Rebeca e Gilda, duas usuárias do PAIST, em uma vendinha na frente do hospital. Elas e ele são abordadas por Vitória, uma participante que exibia poucos símbolos femininos. No rápido encontro anterior às consultas que as três logo fariam, a performance de Vitória é frequentemente questionada por Rebeca e Gilda, participantes mais antigas do programa. Após entreolhar Rebeca com desconfiança, Gilda avisou a Vitória que se ela adentrasse o consultório exibindo seus visíveis signos de masculinidade, como pelos curtos da barba, voz grave e seios pouco visíveis, o médico "não acreditaria que ela era uma trans" (p. 87). "Você é muito masculina", apontou Rebeca. As duas usuárias mais antigas então passam a aconselhar a neófita: "depile com cera quente. A dor é horrível no começo mas depois você acostuma e o resultado é IN-CRÍVEL", "não diga para eles (que seu sentimento transexual começara depois de seu relacionamento corrente)", "Eu digo que desde que eu me conheço por gente (que me reconheço como transexual)", "Acho melhor você não admitir [...] para eles (que tem ereções eventuais)" são alguns dos conselhos - formas entextualizadas de livros, entrevistas e resoluções do CFM e MS que as/os participantes costumam ler e partilhar com as/os outros/as e que explicitam o modelo de transexual verdadeiro. A segunda cena é a consulta de Vitória com Carlos, um dos psiquiatras do programa. A partir de minuciosa transcrição conversacional, Borba demonstra que as respostas de Vitória a Carlos são parte de uma corrente discursiva (Agha 2005) - "isto é, uma série de eventos por meio da qual um signo se movimenta" (Borba, p.91). Por 
exemplo, após ser inquirida por Carlos sobre "quando [ela] chegou à conclusão que [...] apresenta um transtorno de identidade de gênero", a participante responde "desde os sete anos de idade", ao que se seguem detalhes de sua preferência pelas roupas de sua mãe e de seu gosto por "tudo que era coisa de mulher".

Assim, Borba posiciona-se indisciplinarmente na episteme etnometodológica da análise da conversa. Ele demonstra que é necessário ir além do evento circunscrito de fala para compreender melhor os elementos fundamentais da construção turno a turno daquela conversa institucional, responsáveis pela produção de relações intersubjetivas entre interagentes. Trata-se de uma visada fundamental oferecida por este trabalho. A indisciplina de Borba opera nos seguintes termos: somos lembrados pelo autor de que, para Schegloff, pioneiro da análise da conversa, "a construção sociointeracional da realidade" que se lê numa análise conversacional "é entendida como restrita ao aqui-eagora de uma dada interação" (Borba, p.84). No entanto, a visada de que elementos da história de socialização discursiva de um indivíduo têm consequências para a análise o leva a observar que, se a análise conversacional se reduzisse "ao aqui-e-agora da interação", a performance de Vitória "não poderia ser classificada de outra forma senão como um transexual verdadeiro" (p. 91). No entanto, os signos de identidade do aqui-e-agora excedem seu próprio lugar e tempo em vista de sua viagem de outros contextos - como o café com Rebeca, Gilda e Borba - e de seu conflito com o modelo biomédico e metapragmático de autenticidade transexual. As consequências dessa viagem e dessa fricção não são pequenas. Anteriormente à consulta, Carlos havia brevemente interagido com Vitória, ocasião em que remarcaram sua consulta. Após isso, o psiquiatra comentou com Giovani e Roberto, médicos do programa: "Mas ele é homem, parece meio roqueiro!" Para se tornar um sujeito viável no Processo Transexualizador, não parece restar outra alternativa a Vitória a não ser tentar vencer uma longa cadeia de fricções e poderes conectados intertextualmente.

\section{Análise situada de recursos sociolinguísticos}

No Brasil, já são vários os trabalhos que propõem análises situadas ou etnográficas de recursos sociolinguísticos (e.g. Signorini 2002 e 
2008). Epistemicamente, avalio que o grande mérito destes trabalhos está em mostrar, em vez de meramente pressupor, o uso situado de recursos sociolinguístico particulares. Na obra de Borba, tomarei o problema da "mentira", um marcador frequentemente ativado nos diagnósticos da verdade transexual. A análise situada da "mentira" acontece no quinto capítulo, centrado nas figuras de Agnes e Marcia Rejane. Como já mencionado, a primeira delas foi uma participante da Clínica de Gênero da UCLA, cuja interação com Robert Stoller e Harold Garfinkel, professores respectivamente de psiquiatria e sociologia daquela instituição, funcionou como marco para a solidificação de discursos sobre a verdade da transexualidade. A segunda é uma usuária do PAIST com quem Borba interagiu, no palco e nos bastidores do Processo Transexualizador, e que, juntamente com Agnes, desafia o modelo médico-jurídico de verdade transexual. Apesar de estarem distantes temporal e espacialmente - Agnes conheceu Stoller e Garfinkel na UCLA em 1958; Marcia Rejane interagiu com Borba no PAIST em 2010 - as duas transexuais são aproximadas no capítulo pela performance nas "mentiras" contadas aos profissionais aos quais narram suas biografias (e de quem esperam o "passe" para a cirurgia). Entendidas na obra de Borba pela chave foucaultiana das "técnicas de si”, as mentiras que Agnes e Marcia Rejane contaram a seus gatekeepers são também recursos sociolinguísticos empregados estrategicamente, como táticas de sobrevivência em um emaranhado burocrático que estreita formas radicalmente amplas de pertencimento corpóreo. As várias horas de interação entre Garfinkel e Agnes resultam em partes centrais de seu Studies in Ethnometodology (Garfinkel 1967). Nele, Agnes é apresentada como uma "mentirosa de sucesso" (apud Borba, p. 179). Borba detalha os etnométodos habilmente empregados por Agnes em suas entrevistas com Garfinkel - nas quais ela passa por uma pessoa intersexual (ao passo que, de fato, havia tomado remédios de reposição hormonal prescritos para sua mãe, gerando efeitos bioquímicos que contraditoriamente confirmaram sua intersexualidade em exames médicos), homofóbica, antecipadora das "respostas certas", dama prefigurada - e o argumento do etnometodólogo de que eram as mentiras, afinal, que davam "a Agnes e seus parceiros efeitos que conservavam características estáveis de suas interações socialmente estruturadas" (Garfinkel 1967, apud Borba p.179). Conforme análise de consulta de Marcia Rejane com o psiquiatra Fernando, a usuária conta que sempre 
se vira como menina e que tinha aversão a brincar com meninos na infância. Poeticamente, ela demonstra ser uma "narradora habilidosa", exibindo "paralelismo fonológico" em suas construções verbais para Fernando, o que "dá um ritmo stacatto aos seus enunciados e dinamicidade às ações narrativas" (p. 183-184). Borba, no entanto, vai além das fronteiras textuais da consulta e, em entrevista com Marcia Rejane, escuta da usuária que gostava de jogar futebol com os amigos e que se masturbava (e ainda o fazia, quando da entrevista). "Mas você acha que eu vou dizer isso pro Fernando? (...) Ele nunca me daria o laudo, eu nunca faria a cirurgia. Eu preciso dela [da cirurgia] pra ser feliz, pra ter o corpo que eu quero," conclui Marcia Rejane (p. 185). Assim, mentiras são índices de uma sinuosa luta semiótica: por um lado, são estratégias que Agnes e Marcia Rejane utilizam para vencer regimes que estipulam conformidade com trajetórias lineares de identificação entre corpo e desejo; por outro lado, são efeitos da própria metafísica que organiza, num caso, a arregimentação do saber sobre a transexualidade que Stoller e Garfinkel ajudariam a selar, num importante centro de pesquisa estadunidense e, noutro caso, as iterações contemporâneas dessa metafísica da transexualidade. Nos termos dessa metafísica, não corresponder às condições de verdade de um modelo rígido é o equivalente a mentir. Assim, nos termos epistêmicos de Borba, a mentira, se analisada de modo situado, é menos uma questão de acuidade referencial do que um problema de eficácia pragmática.

\section{Escala}

Para concluir esta resenha, devo ainda acrescentar que $O$ (Des) Aprendizado de $\mathrm{Si}$ é um bom exemplo de um trabalho que considera seriamente questões de escala (Carr \& Lempert, 2016) em análises de linguagem. A desconstrução do modelo biomédico de transexualidade é efetuada por Borba a partir da análise de diferentes dimensões do discurso - diferentes escalas - que o permitem entender inicialmente como uma matriz de inteligibilidade heterossexual foi produzida na regulação de corpos transexuais; em seguida, essa matriz (um dispositivo de dimensões transnacionais) é encaixada em outras escalas: por exemplo, na escala da saúde pública brasileira e dos direitos ao cuidado sanitário e na microescala interacional, em que grandes ideologias e 
verdades são feitas, refeitas e desfeitas a partir das contingências do face-a-face e de sua inelutável dependência de outras histórias, outras dimensões, outras biografias. Borba nos convida assim a uma viagem multiescalar que lança luzes sobre a história, a política e a contemporaneidade da transexualidade no Brasil. Nesse passeio por diferentes dimensões da vida social é no mínimo gratificante perceber que o livro é dedicado - e, provavelmente, validado por - uma mulher transexual, Mariah Rafaela Cordeiro Gonzaga da Silva, que certamente reconhece nesta obra uma luta que é não apenas epistêmica, mas também política e afetiva.

\section{Referências}

AGHA, Asif. 2005. Semiosis across encounters. Journal of Linguistic Anthropology 15(1): 1-5.

AUSTIN, John. 1962. How to do things with words. Oxford: Oxford University Press.

CARR, E. Summerson \& Michael Lempert (orgs.). 2016. Scale: Discourse and Dimensions of Social Life. Berkeley: University of California Press.

FABRICIO, Branca. 2014. Transcontextos educacionais: gêneros e sexualidades em trajetórias de socialização na escola. In: Silva, Daniel; Dina Ferreira \& Claudiana Alencar (orgs.). Nova Pragmática: Modos de Fazer. São Paulo: Cortez Editora. p. 145-189.

FABRICIO, Branca. 2017. Linguística aplicada e visão de linguagem: por uma INdisciplinaridade radical. Revista Brasileira de Linguística Aplicada 1: 1-19.

GAFINKEL, Harold. 1967. Studies in Ethnometodology. Malden: Blackwell.

LEMOS, Claudia. 2006. Uma crítica radical à noção de desenvolvimento na Aquisição da Linguagem. In: Lier De Vitto, Maria Francisca \& Lucia Arantes (orgs.). Aquisição, patologias e clínica de linguagem. São Paulo: EDUC/Fapesp. p. 21-32.

MENDOZA-DENTON, Norma. 2008. Homegirls: language and cultural practice among Latina youth gangs. Malden: Blackwell.

MOITA LOPES, Luiz Paulo. 2006a. On Being White, Heterosexual and Male in a Brazilian School: Multiple Positionings in Oral Narratives. In: Finna, Anna; Deborah Schiffrin \& Michael Bamberg (orgs.). Discourse and Identity. Cambridge: Cambridge University Press, 2006. p. 288-313. 
MOITA LOPES, Luiz Paulo. 2006b. Por uma linguística aplicada indisciplinar. São Paulo: Parábola.

OCHS, Elinor. 1992. Indexing gender. In: Duranti, Alessandro \& Charles Goodwin. Orgs. Rethinking Context: Language as an interactive phenomenon. Cambridge: Cambridge University Press. p. 335-359.

OCHS, Elinor \& Bambi Schieffelin. 2008. Language socialization: An historical overview. Encyclopedia of language and education. Vol. 8: 3-15.

SAPIR, Edward. 1933. Language. In: Mandelbaum, D. (ed.). Selected Writings of Edward Sapir in Language, Culture, and Personality. 1949. Berkeley: University of California Press. p. 7-32.

SIGNORINI, Ines. 2002. Por uma teoria da desregulamentação linguística. In: Bagno, Marcos (org.). A linguística da norma. São Paulo: Loyola. p. 93-123.

SIGNORINI, Inês. (org.). 2008. Situar a língua(gem). São Paulo: Parábola.

WORTHAM, Stanton. 2005. Socialization beyond the speech event. Journal of Linguistic Anthropology 15(1): 95-112.

Recebido em: 26/11/2017

Aprovado em: 04/04/2019 